\title{
Evaluation of the Physical, Chemical and Environmental Properties of Ladle Furnace Slag for Their Utilization as Filler in Bituminous Mixtures
}

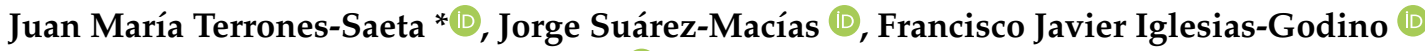 \\ and Francisco Antonio Corpas-Iglesias (D)
}

Department of Chemical, Environmental and Materials Engineering, Scientific and Technological Campus of Linares, Higher Polytechnic School of Linares, University of Jaen, 23700 Linares, Spain; jsuarez@ujaen.es (J.S.-M.); figodino@ujaen.es (F.J.I.-G.); facorpas@ujaen.es (F.A.C.-I.)

* Correspondence: terrones@ujaen.es

check for

updates

Citation: Terrones-Saeta, J.M.; Suárez-Macías, J.; Iglesias-Godino,

F.J.; Corpas-Iglesias, F.A. Evaluation of the Physical, Chemical and Environmental Properties of Ladle Furnace Slag for Their Utilization as Filler in Bituminous Mixtures. Metals 2021, 11, 466. https://doi.org/ $10.3390 /$ met11030466

Academic Editor: Valentina Colla

Received: 6 January 2021

Accepted: 8 March 2021

Published: 12 March 2021

Publisher's Note: MDPI stays neutral with regard to jurisdictional claims in published maps and institutional affiliations.

Copyright: (C) 2021 by the authors. Licensee MDPI, Basel, Switzerland. This article is an open access article distributed under the terms and conditions of the Creative Commons Attribution (CC BY) license (https:/ / creativecommons.org/licenses/by/ $4.0 /)$.

\begin{abstract}
The construction sector is one of the most demanding sectors for materials that exist today. Therefore, in order to avoid the extraction of new raw materials, it is necessary to use waste. This waste must present a series of physical and chemical characteristics that make it suitable for its employment. Therefore, in this investigation, ladle furnace slag is characterized for use as filler in bituminous mixtures. These slags are produced by the metallurgical industry in large quantities and represent a significant environmental problem. The slags were tested by analyzing their chemical composition and elementary physical properties. At the same time, and in order to evaluate the environmental viability, the environmental affections produced by the treatment of this material for its use as filler were calculated. These environmental results were compared with those obtained by processing of conventional filler. The detailed methodology reflected the chemical and physical feasibility of ladle furnace slags for use as filler, as well as the environmental advantage of processing this waste compared to commercial materials. In this way, the suitability of ladle furnace slags for bituminous mixtures and its feasibility for the creation of more sustainable pavements was assessed.
\end{abstract}

Keywords: ladle furnace slag; metallurgical industry; characterization; filler; bituminous mixture; mining waste; life cycle assessment; circular economy; sustainable construction

\section{Introduction}

The evolution of world society results in increased social welfare. This social wellbeing leads to a higher quality of life and a massive use of resources [1]. Consequently, sources of raw materials are becoming increasingly limited [2]. In turn, greater environmental conscience and stricter environmental regulations result in a better use of materials. For this reason, the linear economy used for years is now being abandoned [3].

The old linear economy was based on the extraction of raw materials, the production of outputs and their subsequent disposal. This type of production consumes increasing amounts of materials and generates an enormous amount of waste [4]. In response to this problem, the new circular economy has emerged. In this type of production, waste is the raw material for new materials, which at the end of their working life are in turn the raw material for other materials. In this way, material flows are closed and the environmental impact is reduced [5]. This reduction is due to the disposal of waste in landfills, the use of waste and the elimination of the extraction of new raw materials [6].

One example of this problem is the construction sector. This sector is one of the most polluting, as it requires enormous quantities of raw materials and develops production processes, in most cases, that are not very energy efficient [7]. More specifically, the construction of road infrastructures is an activity that demands important quantities of raw materials. At the same time, it significantly alters the landscape and requires continuous rehabilitation works that consume new materials [8]. 
Moreover, road construction and maintenance are not an activity that can be eliminated [9]. Roads are the most important communication links, they condition economic development and increase the social wellbeing of the population [10]. Therefore, new, more sustainable constructions must be developed as part of the new circular economy [11].

Based on this, several investigations have been carried out in the field of roads in which waste is used to minimize the extraction of raw materials [12]. The waste used has been diverse: ceramic dust [13], discarded plastics [14], ashes from biomasses [15], disused tyres [16], demolition aggregates [17], etc. However, in order to correctly reduce the environmental impact, it is necessary to use waste that creates a material of similar or superior quality than conventional waste. If not, it would be necessary to renovate infrastructure with a lower working life and, subsequently, with higher emissions to the environment [18].

Therefore, the analysis of the physical, chemical and mechanical properties of the waste is essential for its use [19]. In turn, in order to objectively evaluate the environmental suitability of their use, it is necessary to calculate the life cycle assessment [20]. This calculation is carried out for infrastructures incorporating the waste compared to those incorporating conventional materials, accurately determining the environmental benefits of using the waste.

Consequently, this research evaluates the benefits of incorporating ladle furnace slag as a filler in bituminous mixtures. The choice of bituminous mixtures as a waste receiver material is due to the fact that it is the product with the highest economic and environmental cost used in infrastructure. This is due to the fact that in most cases it is necessary to heat large masses of materials to high temperatures [21]. In turn, ladle furnace slag is used because it is a waste product of the metallurgical industry that produces a large proportion. In addition, its properties as a filler were corroborated due to its small particle size [22]. This property makes this material ideal for use; however, its deposition in uncontrolled dumps can create significant environmental problems.

Ladle furnace slag, derived from the refining stage of the steel industry [23], has been used as an additive or partial substitute for cement [24], either for concretes or mortars $[25,26]$, and even for soil stabilization [27]. This has demonstrated the cementitious properties of ladle furnace slag [28].

Accordingly, this waste has interesting particularities for its use as a filler in bituminous mixtures [29-31]. However, it is necessary to carry out a chemical characterization to determine which compounds are pollutants or harmful to the final product; and a physical characterization must be carried out to corroborate that it does indeed have the appropriate properties for use as a filler.

After this characterization of the ladle furnace slag was developed in this research, a life cycle assessment of the slag was carried out in comparison with a commercial filler. In this way, it was possible to objectively evaluate the environmental benefits obtained from the use of this waste in comparison with commercial materials. The SimaPro software was used for this purpose.

Consequently, the novelty of this research consists of the joint evaluation of the properties of ladle furnace slag and the environmental impact of its processing. In this way, the advantages of using slag as a filler in bituminous mixtures can be objectively evaluated, as well as the critical points that researchers or professionals must take into account when using slag in bituminous mixtures.

The results of the studies detailed in the methodology of this research showed a suitable chemical composition of the ladle furnace slag as well as acceptable physical properties for use as a filler in bituminous mixtures. In addition, the life cycle assessment showed a clear reduction in the environmental impact of using the slag as a filler instead of commercial fillers. 


\section{Materials and Methods}

The purpose of the present investigation is the evaluation of the characteristics of ladle furnace slag for use as a filler in bituminous mixtures, as well as the determination of the environmental benefits obtained from its use compared to a commercial filler of a similar quality. To this end, the following sections describe the main materials of this investigation and the methodology followed to corroborate the initial hypothesis.

\subsection{Materials}

The main material analyzed in this investigation was ladle furnace slag. These slags, produced by the metallurgical industry, were taken directly from the producing industry and evaluated over time. Therefore, the characteristics of this by-product were found to be similar in different production batches and the variation was minimal.

This fact is essential for the use of waste. If this were not the case, the variation of the physical or chemical properties would make its use in other final materials unfeasible, since it would continuously change the properties of the final product. This is the case for different types of waste such as sewage sludge, that change their chemical composition depending on the climate, the city and even the time of year.

It should be noted that ladle furnace slag, hereinafter referred to as LFS, comes from the metallurgical industry, which produces steel from scrap. More specifically, the slags evaluated in this research come from companies located in the region of Andalusia, Spain.

Ladle furnace slag belongs to the refining stage, which is carried out in the steel production industry and which is subsequent to the melting stage. In this stage, the ladle furnace is fed by the molten liquid from the electric arc furnace. This liquid is covered with the so-called ladle furnace slag and is continuously agitated by blowing inert gas, usually argon. This process is carried out for the reduction of metal oxides and desulfurization. Therefore, it is usual that these chemical elements are found in the slag. Finally, the slag is removed and deposited in large stockpiles. This type of slag is produced in an amount of approximately 20 to $30 \mathrm{~kg}$ per ton of final steel, depending on the production industry.

The ladle furnace slag, as detailed above, was taken directly from the production company. It has then been subjected to a drying process at $105 \pm 2{ }^{\circ} \mathrm{C}$ for $24 \mathrm{~h}$ to eliminate the humidity. The elimination of water was carried out in order to avoid variables that would disturb the final results. However, the existence of humidity within an industrial process in which ladle furnace slag is used is not negative, but it is a factor to be taken into account.

\subsection{Methodology}

The methodology followed in this research for the corroboration of the initial hypothesis consists of two fundamental stages. On the one hand, the ladle furnace slag is chemically and physically analyzed in order to evaluate its suitability for use as a filler for bituminous mixtures through various usual tests. Subsequently, and based on the results, the environmental benefits obtained from their use are compared with a commercial filler of a similar quality. In the following sections, the tests carried out and the methodology followed for the life cycle assessment, are shown in detail.

\subsubsection{Characterization of Ladle Furnace Slag}

The use of ladle furnace slag as a filler for bituminous mixtures is motivated by its small particle size. However, slag is a waste product from the treatment of scrap and can therefore contain heavy metals that cause a significant environmental impact or impair the quality of the asphalt mix. It is therefore necessary to carry out a series of tests to evaluate the chemical composition of ladle furnace slag.

\section{Chemical Characterization}

For the chemical tests, the slag was dried according to the detailed procedure and then milled to a sample size of less than $0.063 \mathrm{~mm}$. The first of the tests carried out was the 
elemental analysis test. This test reflects the percentages of carbon, nitrogen, hydrogen and sulfur present in the sample, through the combustion of the sample at a temperature of $1000 \pm 5{ }^{\circ} \mathrm{C}$ and the analysis of the gases generated. Therefore, it is essential for organic materials and for chemical compounds that have a tendency to carbonation or hydration. The test was performed with LECO's TruSpec Micro commercial equipment (TruSpec Micro, LECO, St. Joseph, MI, USA).

To determine the elemental composition of the ladle furnace slag, the X-ray fluorescence (XRF) test was performed. This test determines the chemical elements with the highest atomic weight present in the sample as well as the proportion in which they are present. Therefore, it is useful to identify which elements can be harmful to the final product or pollutants if they are not properly treated. The X-ray fluorescence test was performed with the commercial equipment ADVANT'XP+ (ADVANT'XP+, Thermo Fisher, Waltham, MA, USA).

Nevertheless, the reactivity of the elements depends largely on the chemical compound in which they are combined. Therefore, it is necessary to determine the chemical compounds or main phases that exist in the ladle furnace slag. For this purpose, the X-ray diffraction (XRD) test was used to identify the chemical compounds. This test was carried out with the equipment model X'Pert PRO of the commercial brand PANalytical (X'Pert PRO, PANalytical, Malvern, UK).

\section{Physical Characterization}

Once the chemical composition of the ladle furnace slag had been characterized, the physical properties were determined. Since the slag is to be used as a filler in bituminous mixtures, this by-product must have a small particle size. The small particle size makes it possible to combine it with the bitumen and to form a suitable mastic in the asphalt mix capable of withstanding the tensile loads of traffic. Therefore, the ladle furnace slag samples for these physical tests were similar to those obtained after industrial processing. Subsequently, the grading curve obtained was studied.

In turn, the shape and texture of the particles largely condition the behavior of the filler for use in bituminous mixtures. Therefore, and due to the small particle size of the ladle furnace slag, its analysis was carried out using scanning electron microscopy (SEM). This equipment allowed high amplifications to show the surface texture of the slag particles and to provide essential qualitative information. The scanning electron microscope used was a high resolution (FESEM) MERLIN (Carl Zeiss, Oberkochen, Germany) with EDX and WDX (Oxford Analytical, High Wycombe, UK) capabilities.

The ladle furnace slag comes from the deoxidation of steel. Therefore, it is common to find in their chemical composition metallic elements that can influence a higher density. Consequently, it is necessary to calculate the particle density (standard UNE-EN 1097-7) in order to evaluate whether it has a different density to a commercial filler. The variation of the density of the slag should not be a problem in principle, but it is a fact to be taken into account for the dosage of the materials. This is due to the fact that the dosage for the conformation of bituminous mixtures is usually done in mass; therefore, the variation of the density of the slag could produce problems in the final product if it is not taken into account.

In addition, and as mentioned, the filler is the one that is combined with the bitumen to the conformation of the mastic. Therefore, this element conditions the percentage of bitumen. A powdery material, with a small particle size and a high specific surface area will absorb a higher percentage of bitumen, in some cases, this being a limiting factor. In addition, it will produce an incorrect mass dosage due to the formation of particles in suspension in the air due to this process. Therefore, the bulk density in kerosene must be calculated (standard UNE-EN 1097-3) to evaluate this property and corroborate that it is within the established limits.

On the other hand, one of the most conditioning characteristics for the use of a filler is its plasticity index. Plasticity is usually linked to clayey materials that can incur later 
problems of expansiveness or change in volume, thus increasing the probability of the creation of a defective asphalt mixture. It is therefore necessary to carry out the plasticity index test (UNE 103103 and UNE 1031049) to determine that the plasticity of the filler is low and the problems mentioned above will not occur in the final material.

\section{Determination of Leachate}

Finally, and due to the process from which the ladle furnace slag comes, there may be heavy metals that come into contact with water produce contaminating leachates. For this reason, and in order to avoid environmental pollution caused by the use of ladle furnace slag as a filler, the leachate test must be carried out in accordance with the UNE-EN 12457-3 standard. This test provides the concentration of the chemical contaminating elements in the leachate for comparison with the limits set by the regulations in this regard. In this way, it is evaluated whether it is used correctly or should be treated. For the analysis of the leachate, the commercial equipment Agilent 7900 (7900, Agilent, Santa Clara, CA, USA) was used.

\subsubsection{Life Cycle Assessment of Ladle Furnace Slag Compared to Commercial Fillers}

The aim of this section is to determine the environmental benefit of using ladle furnace slag in comparison with commercial fillers.

Consequently, once the slag has been physically and chemically characterized, an environmental assessment is made using the SimaPro software version 8.3.0.0 from PRé Consultants (Amersfoort, the Netherlands). To compare the results, the environmental cost of a commercial limestone filler was also evaluated. There are several reasons for selecting this commercial filler. On the one hand, it is the most common filler used in bituminous mixtures. On the other hand, it has similar physical characteristics to ladle furnace slags. And finally, even though the ladle furnace slag has cementitious properties comparable to cement, an environmental assessment of this material was ruled out, as it would reflect very negative results compared to the slag. This is due to the fact that the production of cement requires the use of high temperature processes. Therefore, the environmental benefits of slag compared to a limestone filler will be compared, even though slag has superior characteristics, as several investigations have shown.

The life cycle assessment methodology was carried out for the detailed materials according to ISO 14040 and ISO 14044. Consequently, several stages were defined within the processing of the material that are essential for obtaining a filler for bituminous mixtures. These stages were selected according to the similarity between processes at the industrial level and in order to be able to differentiate the environmental benefits of ladle furnace slag processing. These stages are:

- Alteration of the landscape. Geology and hydrogeology. Obtaining raw materials for the production of filler for bituminous mixtures has a series of significant impacts that must be taken into account. The first of these is the alteration of the landscape. In this stage the limestone deposit, which can be provided by the filler is located and the landscape is altered by removing the vegetation cover with usual mining equipment. This alteration of the landscape conditions results in various environmental factors. These include noise, fauna, and flora, and in turn, influence underground water flows. Therefore, it is one of the fundamental stages which must be taken into account.

- Raw material extraction. Once the surface is prepared for the extraction of the material, different processes must be developed to extract the raw material. It is usual at this stage to use explosives for rock fragmentation and subsequent collection with mechanical equipment. These collection teams load the transport vehicles which will be taken into account in the subsequent stage. Therefore, explosives produce a number of environmental conditions such as seismic waves, air waves and even dust clouds. In addition, mechanical equipment used for drilling or loading usually consumes fossil fuels. Consequently, a series of emissions into the environment and a significant environmental impact are produced. 
- Freight transport. The loading equipment of the previous stage provides the material to the vehicles for transport. This transport is usually carried out by fossil-fueled vehicles. In addition, these vehicles need a series of roads along which to move. Therefore, there are important environmental effects such as noise, dust and effects on flora and fauna.

- Aggregate processing. Once the material has been received from the quarry, there are plants for the treatment of aggregates and the obtainment of filler for bituminous mixtures. This type of plant has milling equipment arranged in series or in a parallel of enormous dimensions. At the same time, and in order to obtain aggregate circuits that produce a quality filler, there are different conveyor belts with high energy consumption. These types of belts take up considerable space and produce various negative environmental aspects, such as water consumption, noise, dust, etc.

Once the stages have been defined, the methodology to be followed is determined. It should be noted that the stages contemplated for the environmental analysis are sufficient to obtain a quality filler for use in bituminous mixtures, whether from ladle furnace slag or limestone filler. Subsequently, there will be a transport, conformation of bituminous mixtures, a transport, an extending and compacting of the mixtures. These stages are not contemplated within the study, as it is considered that the environmental difference between the two materials would be insignificant for them. The greatest environmental difference exists in the processes of obtaining the material.

The methodology followed for the environmental calculation was CML 2000 in its version 2.05 (Centre for Environmental Studies, Leiden, The Netherlands). This methodology has been used for different reasons.

- It is highly versatile and capable of quantifying different impacts appropriately.

- The data it uses are based on European and even global databases, so the extrapolation of results to different countries is immediate.

- Furthermore, several investigations have used this methodology and have been successful in calculating the environmental impact.

To carry out this methodology of environmental impact analysis, it is necessary to use different real databases in which the impact of each stage is directly measured. The data used for this purpose corresponds to different sources. These sources are detailed below:

- Data from prestigious databases, Ecoinvent v.3.2 (Ecoinvent, Zurich, Switzerland).

- $\quad$ Empirical data measured directly from the different stages.

- Bibliographic data published in various research projects related to the field of study [32-36].

With the premises detailed above, the environmental effects of using ladle furnace slag as a filler for bituminous mixtures and obtaining limestone filler were obtained. In this way it was possible to objectively compare the results and obtain a series of partial conclusions that determined the suitability of the use of this by-product with respect to traditional materials.

\section{Results}

Once the methodology for the chemical and physical analysis of the ladle furnace slag has been determined, as well as for the evaluation of the environmental effect produced by its treatment to obtain a filler that can be used in bituminous mixtures, the results obtained are shown.

\subsection{Characterisation of Ladle Furnace Slag (LFS)}

\subsubsection{Chemical Characterization}

Initially, the tests for chemical characterization were carried out. The first of the tests was the elemental analysis test, showing the results that are reflected in Table 1. 
Table 1. Elemental analysis of ladle furnace slag.

\begin{tabular}{ccccc}
\hline Sample & Nitrogen, $\%$ & Carbon, $\%$ & Hydrogen, $\%$ & Sulfur, $\%$ \\
\hline LFS & $0.007 \pm 0.001$ & $3.405 \pm 0.068$ & $1.386 \pm 0.026$ & $0.000 \pm 0.001$ \\
\hline
\end{tabular}

The analysis test shows a low percentage of the elements under study, thus demonstrating that ladle furnace slag is an inorganic material. In turn, the reduced percentages of carbon and hydrogen seem to correspond to the processes of carbonation and hydration of the chemical compounds in the slag, mainly metal oxides. The reduced percentage of sulfur and nitrogen in the sample should be highlighted, thus ensuring the non-existence of polluting leachates from the use of the slags.

Subsequently, the elemental composition of the ladle furnace slag was analyzed through the XRF test. The results of this test are reflected in Table 2.

Table 2. Results of the X-ray fluorescence of ladle furnace slag.

\begin{tabular}{ccc}
\hline Compound & wt, $\%$ & Est. Error \\
\hline $\mathrm{CaO}$ & 40.19 & 0.25 \\
$\mathrm{MgO}$ & 19.38 & 0.20 \\
$\mathrm{SiO}_{2}$ & 12.49 & 0.17 \\
$\mathrm{Al}_{2} \mathrm{O}_{3}$ & 7.29 & 0.13 \\
$\mathrm{Fe}_{2} \mathrm{O}_{3}$ & 2.38 & 0.08 \\
$\mathrm{MnO}_{\mathrm{S}}$ & 0.936 & 0.047 \\
$\mathrm{TiO}_{2}$ & 0.548 & 0.027 \\
$\mathrm{BaO}$ & 0.486 & 0.024 \\
$\mathrm{Na}_{2} \mathrm{O}$ & 0.240 & 0.012 \\
$\mathrm{Cr}_{2} \mathrm{O}_{3}$ & 0.118 & 0.042 \\
$\mathrm{Cl}$ & 0.1100 & 0.0055 \\
$\mathrm{SrO}$ & 0.0833 & 0.0042 \\
$\mathrm{ZnO}_{\mathrm{K} O}$ & 0.0733 & 0.0037 \\
$\mathrm{KrO}_{2}$ & 0.0681 & 0.0034 \\
$\mathrm{~V}_{2} \mathrm{O}_{5}$ & 0.0506 & 0.0025 \\
$\mathrm{P}$ & 0.0425 & 0.0021 \\
$\mathrm{CuO}$ & 0.0179 & 0.0017 \\
$\mathrm{NiO}$ & 0.0138 & 0.0012 \\
$\mathrm{PbO}$ & 0.0117 & 0.0010 \\
$\mathrm{Nb}_{2} \mathrm{O}_{5}$ & 0.0082 & 0.0011 \\
$\mathrm{MoO}_{3}$ & 0.0048 & 0.0010 \\
$\mathrm{Co}_{3} \mathrm{O}_{4}$ & 0.0046 & 0.0006 \\
$\mathrm{SeO}_{2}$ & 0.0028 & 0.0009 \\
& 0.0021 & 0.0009 \\
& 0.0012 & 0.0005 \\
\hline
\end{tabular}

The elemental composition determined through the XRF test showed the majority of chemical elements such as calcium, magnesium, silicon and aluminum. These elements are directly derived from the materials added to the ladle furnace for the development of the refining stage for the treatment of scrap. It is worth noting the important existence of iron, this being a common occurrence, as the slag is derived from the steel formation process. The other elements are found in such a reduced proportion that they do not imply important changes in the physical characteristics. Nevertheless, the leaching of the slag from the ladle furnace is subsequently analyzed to corroborate that no environmental pollution is produced by its use.

As commented in the methodology, the chemical elements have more or less activity and, consequently, can produce greater or lesser problems in the final material, depending on the chemical compound in which they are combined. For the determination of the chemical compounds or main phases of the slag, the XRD test was carried out. This test reflected the diffractogram shown in Figure 1. 


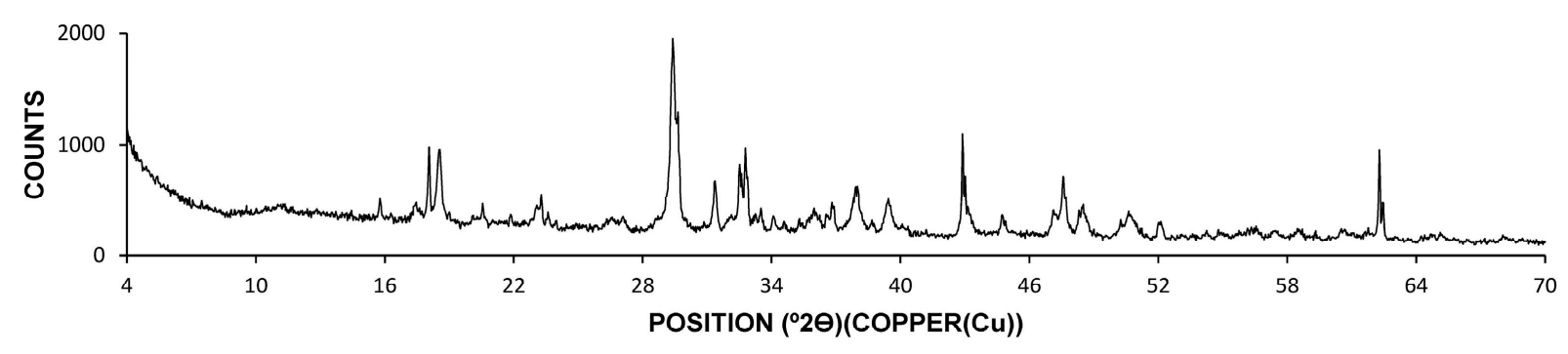

Figure 1. Results of X-ray diffraction of ladle furnace slag.

The diffractogram of the ladle furnace slag reflects a high content of amorphous or non-diffracting material. The main phases are identified as calcite, olivine, periclase and brucite. Portlandite and magnesium silicates are also found in a smaller proportion. The silicates identified in the sample may be responsible for the cementitious properties. At the same time, it should be noted that calcite is produced by carbonation, carbon dioxide uptake from the atmosphere, so this chemical compound is more stable than calcium oxide and does not produce expansivity problems. On the other hand, the periclase formed by magnesium oxide undergoes a slower process of carbonation, so its wrapping with the bitumen of the bituminous mix will prevent the carbonation of this oxide, avoiding possible problems of expansivity, unlike what happens with concrete. Brucite is a more stable chemical compound due to the hydration of the magnesium oxide.

\subsubsection{Physical Characterization}

Once the chemical composition of the ladle furnace slag has been analyzed, and its chemical viability determined for use as a filler in bituminous mixtures, the physical properties are determined. The first of the physical tests carried out was to determine the size of the particles. This test is essential, as ladle furnace slag is expected to perform the function of filler and must therefore have a reduced particle size. It should be noted that ladle furnace slags taken directly from the factory contained particles larger than $2 \mathrm{~mm}$ and smaller than $6 \mathrm{~mm}$. These particles accounted for less than $14 \%$ of the total mass of the slag. Therefore, it was estimated that they had to be removed by a subsequent sieving process and that they accounted for a negligible percentage. The grading curve of the ladle furnace slag, without taking into account the particles with a size greater than $2 \mathrm{~mm}$, is shown in Figure 2.

LADLE FURNACE SLAG GRADING CURVE

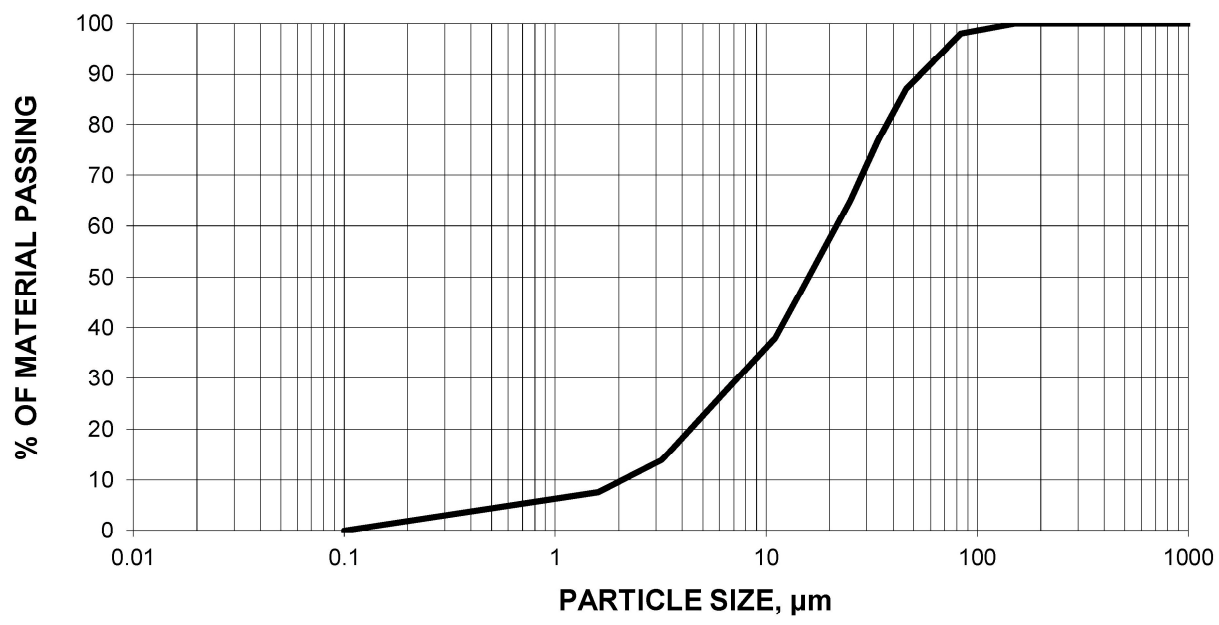

Figure 2. Ladle furnace slag grading curve. 
The grading curve of the ladle furnace slag shows a significant percentage of particles smaller than $0.063 \mathrm{~mm}$, this percentage being higher than the $70 \%$ limited by European regulations. Therefore, its use as a filler in bituminous mixtures is suitable, provided that particles larger than $2 \mathrm{~mm}$ are removed. The highest percentage of particles has a size between 2 and 50 microns, corroborating the suitability of the slag for use as filler in bituminous mixtures. However, the bulk density test on kerosene reflected the suitability of the specific surface of the ladle furnace slag.

Subsequently, the SEM test of the ladle furnace slag was carried out. This test reflects, through large amplifications, the texture of the slag, and can provide very important qualitative information. The images taken from the SEM test for ladle furnace slag are shown in Figure 3.

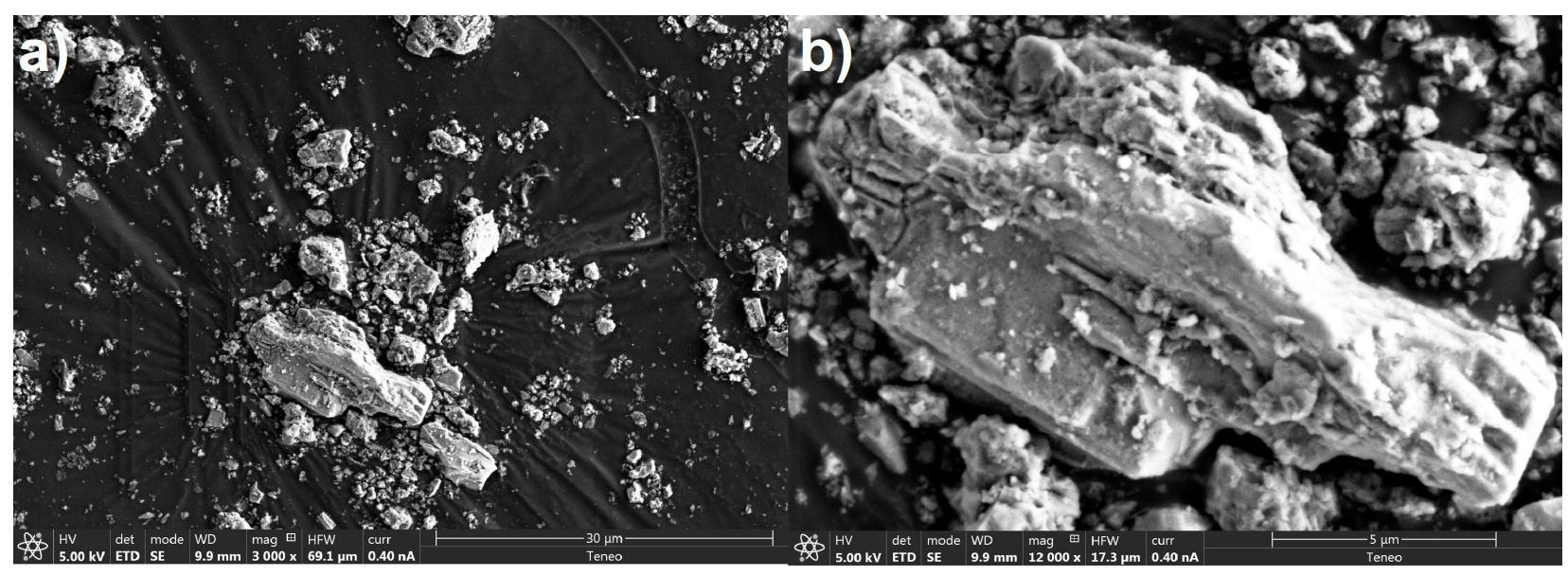

Figure 3. Images of ladle furnace slag with scanning electron microscope at different magnifications in the secondary option. (a) $3000 \times$; (b) $12,000 \times$.

SEM images show different aspects of ladle furnace slag. On the one hand, it has a small particle size, since it has been necessary to use large magnifications for their observation. On the other hand, it has a fairly regular surface texture, without the existence of micropores. Therefore, the detailed qualitative aspects obtained by microscopy coincide with the results of the chemical composition and, in turn, corroborate the suitability of the ladle furnace slag as a filler for bituminous mixtures.

On the other hand, the particle density, bulk density in kerosene and plasticity index tests were carried out. The results of these tests are shown in Table 3.

Table 3. Density and plasticity tests for the fine portion of ladle furnace slag.

\begin{tabular}{ccc}
\hline Test & Standard & Value/Unit \\
\hline Particle density & UNE-EN 1097-7 & $2.71 \pm 0.07 \mathrm{t} / \mathrm{m}^{3}$ \\
Bulk density & UNE-EN 1097-3 & $0.75 \pm 0.01 \mathrm{t} / \mathrm{m}^{3}$ \\
Plasticity index & UNE 103103/UNE 103104 & No plasticity \\
\hline
\end{tabular}

The particle density of the ladle furnace slag does not differ from the density of a commercial filler, the density of the latter being $2.65 \mathrm{t} / \mathrm{m}^{3}$. Therefore, no special measures or volumetric corrections are required for its use, and it can be dosed in mass like a conventional filler. On the other hand, the results of the apparent density in kerosene show the suitability of the slag as a filler for bituminous mixtures. The result obtained is between the limits of $0.5 \mathrm{t} / \mathrm{m}^{3}$ and $0.8 \mathrm{t} / \mathrm{m}^{3}$, reflecting that it is not a powdery material and that it has a specific surface suitable for absorbing bitumen. Finally, the plasticity index reflects a null value. This fact was to be expected due to the cementitious properties of the slag 
demonstrated by different authors, thus avoiding the production of subsequent problems of expansiveness due to clayey particles.

\subsubsection{Determination of Leachate}

Finally, and with the aim of corroborating that the use of ladle furnace slag does not produce polluting leachate, the leaching test was carried out. The results of this test are shown in Table 4.

Table 4. Concentration of chemical elements in the leaching of ladle furnace slag.

\begin{tabular}{ccc}
\hline Element & LFS, $\mathbf{~ g / k g}$ & Maximum Limits, $\mathbf{~ g / k g}$ \\
\hline $\mathrm{Ba}$ & $12.784 \pm 0.306$ & 17.000 \\
$\mathrm{Cd}$ & $0.000 \pm 0.001$ & 0.009 \\
$\mathrm{Cr}$ & $0.007 \pm 0.001$ & 0.500 \\
$\mathrm{Mo}$ & $0.092 \pm 0.002$ & 0.500 \\
$\mathrm{Ni}$ & $0.002 \pm 0.001$ & 0.400 \\
$\mathrm{~Pb}$ & $0.018 \pm 0.001$ & 0.500 \\
$\mathrm{Se}$ & $0.080 \pm 0.002$ & 0.100 \\
$\mathrm{~V}$ & $0.008 \pm 0.001$ & 1.300 \\
$\mathrm{Zn}$ & $0.021 \pm 0.001$ & 1.200 \\
$\mathrm{As}$ & $0.000 \pm 0.001$ & 0.500 \\
$\mathrm{Cu}$ & $0.066 \pm 0.002$ & 2.000 \\
$\mathrm{Hg}$ & $0.000 \pm 0.001$ & 0.010 \\
$\mathrm{Sb}$ & $0.011 \pm 0.001$ & 0.060 \\
\hline
\end{tabular}

The leaching test showed that although the ladle furnace slag is a by-product of the metallurgical industry, there were no high concentrations of heavy metals in the leachate. Therefore, and according to the limitations established by Spanish regulations, their use in bituminous mixtures is suitable, even more so when they are found in combination with bitumen and their leaching is made difficult.

In short, and according to the results of the chemical and physical tests carried out, it can be stated that ladle furnace slag is suitable for use as a filler in bituminous mixtures.

\subsection{Life Cycle Assessment of Ladle Furnace Slag Compared to Commercial Fillers}

This section describes the results of the life cycle assessment of ladle furnace slag for use as filler in bituminous mixtures. According to the results obtained in the physicalchemical characterization of the slag, it was decided to compare the effect of this waste with the environmental effect produced by processing and obtaining a limestone filler. It should be noted that ladle furnace slag has cementitious properties that have a positive influence on the quality of the bituminous mix, and therefore its use as a filler develops better properties for the final material.

Among the different impacts, provided by the life cycle assessment methodology detailed above, one of the most important is global warming. This impact is quantified through kilograms of $\mathrm{CO}_{2}$ equivalent. Therefore, and in order to evaluate which of the different stages produces the highest emissions, the $\mathrm{CO}_{2}$ emissions, according to the different stages, have been detailed in Figure 4.

The results of the environmental impact, due to global warming, of limestone filler show a higher percentage of $\mathrm{CO}_{2}$ emissions in the aggregate processing stage. This result is logical if we take into account the huge equipment required for the reduction of the particle size received from the quarry. Subsequently, and with lower emissions, there is the stage of mineral extraction. This stage produces significant emissions due to the use of explosives and the use of fossil fuel-powered machinery to load the extracted material. Finally, and with similar environmental effects, there are the stages of landscape alteration and transport of materials. Both stages produce important contamination, although they are necessary and inevitable for the processing of raw materials and the obtainment of limestone filler. 


\section{Global warming by processing commercial limestone filler}

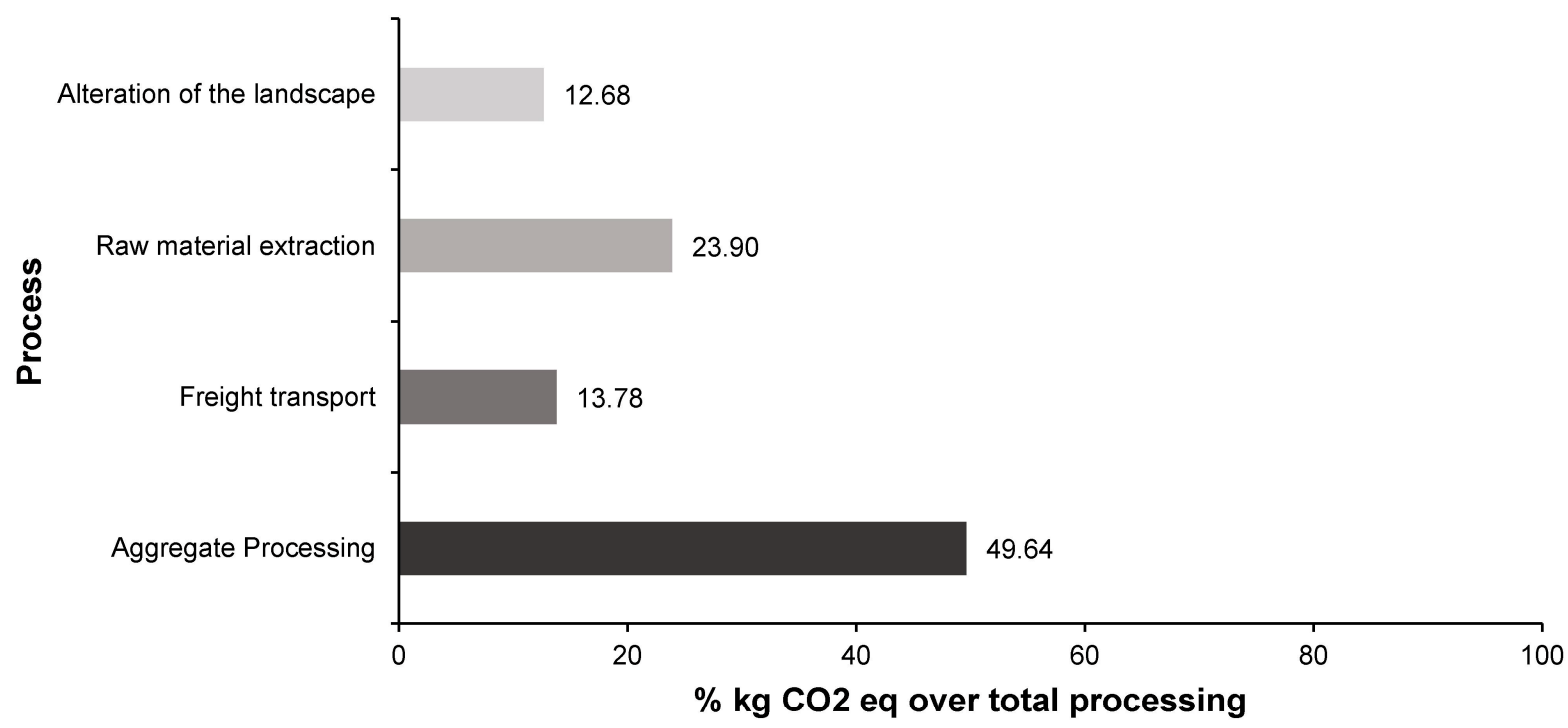

Figure 4. Percentages of $\mathrm{kg}$ of $\mathrm{CO}_{2}$ by stages of the process of obtaining commercial limestone filler for use in bituminous mixtures.

Next, with the aim of comparing the environmental impact of the processing of ladle furnace slag with limestone filler, Figure 5 shows the differences in $\mathrm{CO}_{2}$ emissions according to the material used.

\section{Global warming \\ Limestone Filler Vs. Ladle Furnace Slags}

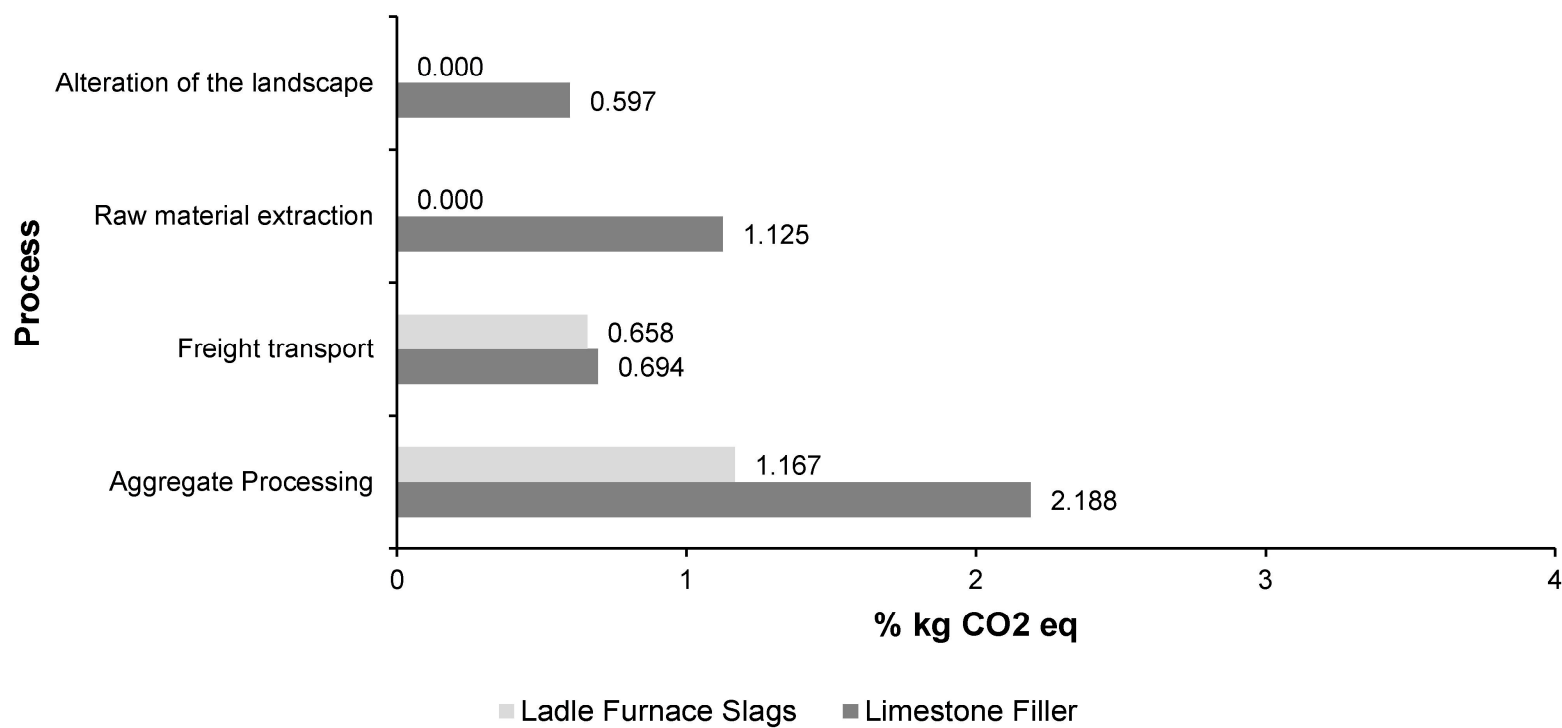

Figure 5. Global warming emissions in kilograms of $\mathrm{CO}_{2}$ equivalent for ladle furnace slag and commercial limestone filler.

Figure 5 shows how the landscape alteration stage in the ladle furnace slag produces null emissions. This is due to the fact that the slag is an industrial by-product, so there is no need to alter the landscape, geology or hydrogeology. The same applies to the stage of extraction of materials. In this stage the limestone filler provides high emissions, while 
the ladle furnace slag has null emissions. As in the previous case, these null emissions are due to the fact that the ladle furnace slag is not required to be extracted, but is produced in the metallurgical industry. On the other hand, the transport stage develops similar $\mathrm{CO}_{2}$ emissions between the ladle furnace slag and the limestone filler. However, the emissions for the slags are slightly lower due to their smaller particle size and consequently a better use of the vehicle volume. Finally, in the processing stage, there is an important difference between the slag and the limestone filler. This is due to the fact that the limestone filler must be crushed with different equipment to reduce the particle size until a quality filler is obtained. On the other hand, the ladle furnace slag has a suitable particle size for its use, so it is simply necessary to sift it to remove particles larger than $2 \mathrm{~mm}$. Therefore, the results for emissions in kilograms of $\mathrm{CO}_{2}$ equivalent for the impact of global warming show a clear environmental advantage of ladle furnace slag over commercial limestone filler, reflecting total process values of 1.82 and 4.60 respectively. In other words, there is a $60 \%$ reduction in emissions of kilograms of $\mathrm{CO}_{2}$ equivalent for the use of ladle furnace slag instead of a commercial limestone filler.

In addition, the methodology followed in this research, through the SimaPro software, calculates another series of environmental conditions that are interesting to quantify and compare between ladle furnace slag and a commercial filler. These conditions and their quantification for each material are detailed in Table 5.

Table 5. Impacts associated with the processing of natural siliceous aggregates and electric arc furnace slags for use in bituminous mixtures.

\begin{tabular}{cccc}
\hline Impact Category & Unit & Limestone Filler & LFS \\
\hline Abiotic depletion & $\mathrm{kg} \mathrm{Sb} \mathrm{eq}$ & 0.048 & 0.014 \\
Acidification & $\mathrm{kg} \mathrm{SO}_{2}$ eq & 0.047 & 0.009 \\
Eutrophication & $\mathrm{kg} \mathrm{PO}_{4}$ eq & 0.012 & 0.002 \\
Human toxicity & $\mathrm{kg} \mathrm{1.4-DB} \mathrm{eq}$ & 3.561 & 0.985 \\
Fresh water aquatic ecotox. & $\mathrm{kg} \mathrm{1.4-DB} \mathrm{eq}$ & 0.710 & 0.165 \\
Marine aquatic ecotoxicity & $\mathrm{kg} \mathrm{1.4-DB} \mathrm{eq}$ & 1479.803 & 379.969 \\
Terrestrial ecotoxicity & $\mathrm{kg} \mathrm{1.4-DB} \mathrm{eq}$ & 0.010 & 0.004 \\
Photochemical oxidation & $\mathrm{kg} \mathrm{C}_{2} \mathrm{H}_{4} \mathrm{eq}$ & 0.0010 & 0.0003 \\
\hline
\end{tabular}

The emissions for the different environmental conditions detailed in Table 5 show that in all cases the processing of ladle furnace slag as filler for bituminous mixtures has important environmental advantages over the processing of commercial fillers. However, for a more graphic comparison, Figure 6 shows the percentage of emissions from the processing of the two materials in percentages, with $100 \%$ being the sum of both emissions.

As can be seen in Figure 6, eutrophication is the impact that is most reduced by processing ladle furnace slag instead of limestone filler. Next, and with approximate values, the impacts of acidification and fresh water aquatic ecotoxicity. They also show the environmental advantage of using ladle furnace slag. Finally, the impact that represents the least reduction is that of terrestrial ecotoxicity, with a reduction of approximately $60 \%$.

In short, and in view of the results obtained from the comparison of emissions in the process of obtaining filler through ladle furnace slag or limestone, it can be stated that the use of slag produces a considerable environmental reduction with different impacts. 


\section{Baseline impact categories analyzed Limestone Filler Vs. Ladle Furnace Slags}

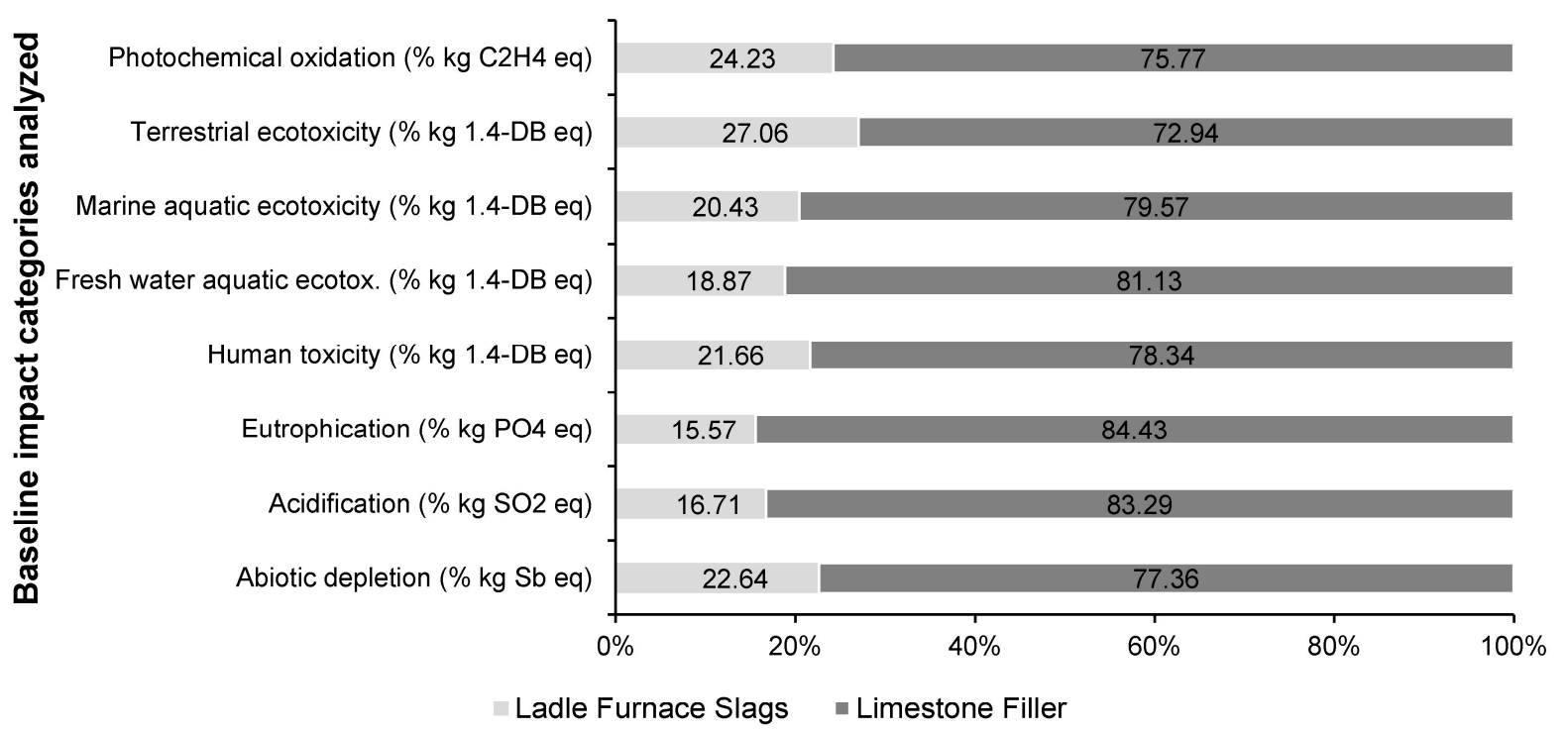

Figure 6. Percentages of emissions from various impacts for commercial limestone filler and ladle furnace slag.

\section{Conclusions}

The results of the tests carried out in the methodology and in the life cycle assessment reflect a series of partial conclusions that are detailed below:

- The chemical composition of ladle furnace slag reflects that it is an inorganic material, with low percentages of sulfur and nitrogen. In addition, the main elements are calcium, silicon, aluminum and iron, forming phases such as calcite, olivine, periclase and brucite. In smaller proportions, portlandite and magnesium silicates are found.

- Ladle furnace slag has a small particle size, with particles smaller than $0.063 \mathrm{~mm}$ accounting for the largest percentage in the sample.

- The particle density of ladle furnace slag does not differ from that of a commercial filler. Furthermore, the bulk density reflects a material suitable for use as a filler, not being excessively pulverulent. The null plasticity of the slag should be highlighted, thus avoiding subsequent problems of expansiveness.

- The heavy metal leachates in the ladle furnace slag have concentrations lower than those limited by environmental regulations.

- A life cycle assessment has shown that processing ladle furnace slag in comparison with processing an calcareous rock to obtain filler reduces emissions of kilograms of $\mathrm{CO}_{2}$ equivalent by $60 \%$.

In summary, and according to the partial conclusions detailed above, it can be stated that the use of ladle furnace slag as filler for bituminous mixtures is appropriate. In addition, it produces less of an environmental impact than commercial fillers, so its use leads to sustainable materials and are framed within the circular economy. At the same time, it avoids the deposition of this waste in a landfill, provides it with a new working life, avoids the extraction of raw materials, avoids the alteration of the landscape and creates new sustainable materials for a sector as contaminating as the construction sector.

Author Contributions: Conceptualization, F.A.C.-I., F.J.I.-G., J.M.T.-S. and J.S.-M.; methodology, F.A.C.-I., F.J.I.-G., J.M.T.-S. and J.S.-M.; software, J.M.T.-S. and J.S.-M.; validation, F.A.C.-I. and F.J.I.-G.; formal analysis, F.A.C.-I. and F.J.I.-G.; investigation, J.M.T.-S. and J.S.-M.; resources, F.A.C.-I.; data curation, F.J.I.-G.; writing—original draft preparation, J.S.-M.; writing—review and editing, J.M.T.-S.; visualization, J.M.T.-S.; supervision, F.A.C.-I.; project administration, J.S.-M.; funding acquisition, F.A.C.-I. All authors have read and agreed to the published version of the manuscript. 
Funding: This research received no external funding.

Institutional Review Board Statement: Not applicable.

Informed Consent Statement: Not applicable.

Data Availability Statement: Data are contained within the article.

Acknowledgments: In Technical and human support provided by CICT of Universidad de Jaén (UJA, MINECO, Junta de Andalucía, FEDER) is gratefully acknowledged.

Conflicts of Interest: The authors declare no conflict of interest.

\section{References}

1. Khan, J.; Hildingsson, R.; Garting, L. Sustainable Welfare in Swedish Cities: Challenges of Eco-Social Integration in Urban Sustainability Governance. Sustainability 2020, 12, 383. [CrossRef]

2. Naqi, A.; Jang, J. Recent Progress in Green Cement Technology Utilizing Low-Carbon Emission Fuels and Raw Materials: A Review. Sustainability 2019, 11, 537. [CrossRef]

3. Rodias, E.; Aivazidou, E.; Achillas, C.; Aidonis, D.; Bochtis, D. Water-Energy-Nutrients Synergies in the Agrifood Sector: A Circular Economy Framework. Energies 2020, 14, 159. [CrossRef]

4. Viles, E.; Santos, J.; Arévalo, T.F.; Tanco, M.; Kalemkerian, F. A New Mindset for Circular Economy Strategies: Case Studies of Circularity in the Use of Water. Sustainability 2020, 12, 9781. [CrossRef]

5. Kardung, M.; Cingiz, K.; Costenoble, O.; Delahaye, R.; Heijman, W.; Lovrić, M.; van Leeuwen, M.; M’Barek, R.; van Meijl, H.; Piotrowski, S.; et al. Development of the Circular Bioeconomy: Drivers and Indicators. Sustainability 2021, 13, 413. [CrossRef]

6. Amin, M.; Tayeh, B.A.; Agwa, I.S. Effect of using mineral admixtures and ceramic wastes as coarse aggregates on properties of ultrahigh-performance concrete. J. Clean. Prod. 2020, 273, 123073. [CrossRef]

7. Huang, Z.; Fan, H.; Shen, L.; Du, X. Policy instruments for addressing construction equipment emission-A research review from a global perspective. Environ. Impact Assess. Rev. 2021, 86, 106486. [CrossRef]

8. Giunta, M. Assessment of the Impact of $\mathrm{CO}, \mathrm{NO}_{\mathrm{x}}$ and PM10 on Air Quality during Road Construction and Operation Phases. Sustainability 2020, 12, 10549. [CrossRef]

9. Li, H.; Liu, Y.; Peng, K. Characterizing the relationship between road infrastructure and local economy using structural equation modeling. Transp. Policy 2018, 61, 17-25. [CrossRef]

10. Terrones-Saeta, J.M.; Suárez-Macías, J.; Iglesias-Godino, F.J.; Corpas-Iglesias, F.A. Development of High Resistance Hot Mix Asphalt with Electric Arc Furnace Slag, Ladle Furnace Slag, and Cellulose Fibers from the Papermaking Industry. Appl. Sci. 2021, 11, 399. [CrossRef]

11. Attahiru, Y.B.; Aziz, M.M.A.; Kassim, K.A.; Shahid, S.; Wan Abu Bakar, W.A.; NSashruddin, T.F.; Rahman, F.A.; Ahamed, M.I. A review on green economy and development of green roads and highways using carbon neutral materials. Renew. Sustain. Energy Rev. 2019, 101, 600-613. [CrossRef]

12. Giro-Paloma, J.; Formosa, J.; Chimenos, J.M. Granular Material Development Applied in an Experimental Section for Civil Engineering Purposes. Appl. Sci. 2020, 10, 6782. [CrossRef]

13. Andrzejuk, W.; Barnat-Hunek, D.; Góra, J. Physical Properties of Mineral and Recycled Aggregates Used to Mineral-Asphalt Mixtures. Materials 2019, 12, 3437. [CrossRef]

14. White, G. A Synthesis on the Effects of Two Commercial Recycled Plastics on the Properties of Bitumen and Asphalt. Sustainability 2020, 12, 8594. [CrossRef]

15. Ameli, A.; Babagoli, R.; Norouzi, N.; Jalali, F.; Poorheydari Mamaghani, F. Laboratory evaluation of the effect of coal waste ash (CWA) and rice husk ash (RHA) on performance of asphalt mastics and Stone matrix asphalt (SMA) mixture. Constr. Build. Mater. 2020, 236, 117557. [CrossRef]

16. Mohajerani, A.; Burnett, L.; Smith, J.V.; Markovski, S.; Rodwell, G.; Rahman, M.T.; Kurmus, H.; Mirzababaei, M.; Arulrajah, A.; Horpibulsuk, S.; et al. Recycling waste rubber tyres in construction materials and associated environmental considerations: A review. Resour. Conserv. Recycl. 2020, 155, 104679. [CrossRef]

17. Sánchez-Cotte, E.H.; Pacheco-Bustos, C.A.; Fonseca, A.; Triana, Y.P.; Mercado, R.; Yepes-Martínez, J.; Lagares Espinoza, R.G. The Chemical-Mineralogical Characterization of Recycled Concrete Aggregates from Different Sources and Their Potential Reactions in Asphalt Mixtures. Materials 2020, 13, 5592. [CrossRef]

18. Pouranian, M.R.; Shishehbor, M. Sustainability Assessment of Green Asphalt Mixtures: A Review. Environments 2019, 6, 73. [CrossRef]

19. Veropalumbo, R.; Russo, F.; Viscione, N.; Biancardo, S.A.; Oreto, C. Investigating the rheological properties of hot bituminous mastics made up using plastic waste materials as filler. Constr. Build. Mater. 2020, 270, 121394. [CrossRef]

20. Praticò, F.G.; Giunta, M.; Mistretta, M.; Gulotta, T.M. Energy and Environmental Life Cycle Assessment of Sustainable Pavement Materials and Technologies for Urban Roads. Sustainability 2020, 12, 704. [CrossRef]

21. Sollazzo, G.; Longo, S.; Cellura, M.; Celauro, C. Impact Analysis Using Life Cycle Assessment of Asphalt Production from Primary Data. Sustainability 2020, 12, 10171. [CrossRef] 
22. Setién, J.; Hernández, D.; González, J.J. Characterization of ladle furnace basic slag for use as a construction material. Constr. Build. Mater. 2009, 23, 1788-1794. [CrossRef]

23. Escorias Blancas I CEDEX. Available online: http:/ / www.cedexmateriales.es/catalogo-de-residuos/25/escorias-de-aceria-dehorno-de-arco-electrico/valorizacion/propiedades-/46/escorias-blancas.html (accessed on 6 January 2021).

24. Perez-Garcia, F.; Parron-Rubio, M.E.; Garcia-Manrique, J.M.; Rubio-Cintas, M.D. Study of the Suitability of Different Types of Slag and Its Influence on the Quality of Green Grouts Obtained by Partial Replacement of Cement. Materials 2019, 12, 1166. [CrossRef] [PubMed]

25. Brand, A.S.; Fanijo, E.O. A Review of the Influence of Steel Furnace Slag Type on the Properties of Cementitious Composites. Appl. Sci. 2020, 10, 8210. [CrossRef]

26. Parron-Rubio, M.E.; Perez-Garcia, F.; Gonzalez-Herrera, A.; Oliveira, M.J.; Rubio-Cintas, M.D. Slag Substitution as a Cementing Material in Concrete: Mechanical, Physical and Environmental Properties. Materials 2019, 12, 2845. [CrossRef]

27. Manso, J.M.; Ortega-López, V.; Polanco, J.A.; Setién, J. The use of ladle furnace slag in soil stabilization. Constr. Build. Mater. 2013, 40, 126-134. [CrossRef]

28. Najm, O.; El-Hassan, H.; El-Dieb, A. Ladle slag characteristics and use in mortar and concrete: A comprehensive review. J. Clean. Prod. 2021, 288, 125584. [CrossRef]

29. Terrones-Saeta, J.M.; Suárez-Macías, J.; Iglesias-Godino, F.J.; Corpas-Iglesias, F.A. Evaluation of the Use of Electric Arc Furnace Slag and Ladle Furnace Slag in Stone Mastic Asphalt Mixes with Discarded Cellulose Fibers from the Papermaking Industry. Metals 2020, 10, 1548. [CrossRef]

30. Terrones-Saeta, J.M.; Iglesias-Godino, F.J.; Corpas-Iglesias, F.A.; Martínez-García, C. Study of the Incorporation of Ladle Furnace Slag in the Manufacture of Cold In-Place Recycling with Bitumen Emulsion. Materials 2020, 13, 4765. [CrossRef] [PubMed]

31. Terrones-Saeta, J.M.; Suárez-Macías, J.; Iglesias-Godino, F.J.; Corpas-Iglesias, F.A. Development of Porous Asphalt with Bitumen Emulsion, Electric arc Furnace Slag and Cellulose Fibers for Medium Traffic Roads. Minerals 2020, 10, 872. [CrossRef]

32. Bianco, I.; Blengini, G.A. Life Cycle Inventory of techniques for stone quarrying, cutting and finishing: Contribution to fill data gaps. J. Clean. Prod. 2019, 225, 684-696. [CrossRef]

33. Stafford, F.N.; Dias, A.C.; Arroja, L.; Labrincha, J.A.; Hotza, D. Life cycle assessment of the production of Portland cement: A Southern Europe case study. J. Clean. Prod. 2016, 126, 159-165. [CrossRef]

34. Josa, A.; Aguado, A.; Cardim, A.; Byars, E. Comparative analysis of the life cycle impact assessment of available cement inventories in the EU. Cem. Concr. Res. 2007, 37, 781-788. [CrossRef]

35. Kittipongvises, S. Assessment of environmental impacts of limestone quarrying operations in Thailand. Environ. Clim. Technol. 2017, 20, 67-83. [CrossRef]

36. Fugiel, A.; Burchart-Korol, D.; Czaplicka-Kolarz, K.; Smoliński, A. Environmental impact and damage categories caused by air pollution emissions from mining and quarrying sectors of European countries. J. Clean. Prod. 2017, 143, 159-168. [CrossRef] 